\title{
An Analysis of the Translation Strategies Used to Translate, from English into Nyanja, Zambia's "A Simple Guide to the Anti Gender Based Violence (GBV) Act”
}

\author{
Gerald Chishiba, Regina Mvula \\ Department of Languages and Literature, School of Humanities and Social Sciences, University of Zambia, Lusaka, Zambia
}

Email address:

geraldchishiba@yahoo.co.uk (G. Chishiba),gmvula89@gmail.com (R. Mvula)

\section{To cite this article:}

Gerald Chishiba, Regina Mvula. An Analysis of the Translation Strategies Used to Translate, from English into Nyanja, Zambia's “A Simple Guide to the Anti Gender Based Violence (GBV) Act”. International Journal of Applied Linguistics and Translation.

Vol. 3, No. 1, 2017, pp. 10-15. doi: 10.11648/j.ijalt.20170301.12

Received: March 15, 2017; Accepted: March 24, 2017; Published: April 25, 2017

\begin{abstract}
The aim of this article is to identify the strategies used to translate an official Zambian document titled "A Simple Guide to the Anti GBV Act". The skopos theory by the German translator Vermeer (1978) and Vinay and Darbelnet's (1973) taxonomy were applied in the analysis of the text. The results revealed that literal translation was the most frequently used strategy. The results further revealed that borrowing, addition and generalisation were also used in line with Vinay and Darbelnet's taxonomy. Other translation strategies found were Schjoldager's (2008) direct transfer and baker's (1992) use of less expressive words and omission. Our conclusion is that the translation strategies that were used when translating the document "A Simple Guide to the Anti GBV Act" from English into Nyanja fulfilled the Skopos theory requirement as far as the analysis of a text is concerned. According to the Skopos Theory, a translator is expected to provide a translation that is easier to understand in the target language and culture. Furthermore, the results revealed that most of the text was clearly reversible.
\end{abstract}

Keywords: Translation Strategies, Skopos Theory, Darbelnet's Taxonomy, Anti GBV Act and Nyanja

\section{Introduction}

Gender based violence (GBV) is an issue that has existed from times immemorial, not only in Zambia, but all over the world. Zambia as a country, in response to gender based violence, enacted the Anti-Gender Based Violence Act in 2011. This act aimed at providing protection and support for survivors of GBV as well as establishing shelters for survivors. Furthermore, the act provided for the establishment of the anti-gender based violence committee and the anti-gender based violence fund.

However, despite the enactment of the anti GBV Act of 2011, Zambia has been found to be among the many countries which are still experiencing high levels of GBV. The Young Women Christian Association of Zambia (YWCA) recorded 3,887 cases of GBV countrywide in the period between January and June 2012. As a result, YWCA, in collaboration with the Zambia National Education Coalition (ZANEC) made the following recommendations to
Government:

1. The implementation of the Anti GBV Act should be amplified by government and other stakeholders so that the provisions contained therein can benefit the people of Zambia.

2. The established Anti GBV Committee should assume its responsibility of effectively coordinating a national response to GBV.

3. Adequate resources should be allocated for the establishment of the Anti GBV fund and efficient operation of law enforcement agencies to enable them effectively respond to GBV cases as stipulated in the Anti GBV Act.

4. The Anti-Gender Based Violence Act and its simplified version should be translated into local languages and be disseminated to the general public country wide through intensified awareness and sensitization programmes. 
5. Men, especially those in leadership and high profile positions should speak out and strongly condemn vices of gender based violence and also demonstrate this by visibly serving as role models and ambassadors within their communities on GBV issues.

6. Anti-Gender Based Violence Campaigns should not be seen as a confrontational campaign by women targeting men but rather a collaboration of efforts by all members of society.

The fourth recommendation is the basis of our study. This current study has looked at the translation techniques or strategies that were used to translate the simplified version of the Anti GBV Act from English into Nyanja. Its primary focus is to investigate what strategies were used in the process of translating the simplified version of Anti GBV act in English into Nyanja. The skopos theory was applied in the analysis of the text. However, since the Skopos theory does not pay sufficient attention to the linguistic nature of the Source Text (ST) nor to the reproduction of micro level features in the Target Text (TT), the translation strategies will be explained using Vinay and Darbelnet taxonomy that looks not only at the process but the product as well. However, before explaining the skopos theory and Vinay and Darbelnet Taxonomy there is need to define what we mean by legal translation. Consequently, the next section will focus on the issue of Legal translation. The Skopos theory and Vinay and Darbelnet taxonomy have been explained in the 3.0 section.

\section{Literature Review}

Most of the studies that have been carried out on Anti Gender Based Violence in Africa focus more on the social practices that either prevent or encourage gender based violence as well as how the courts of law handle GBV related cases. However, with relation to that current article, the following scholars are worth mentioning. Bergli (2013) carried out research on the prevailing situation of GBV cases in south Sudan. He focused his study on the Transitional Constitution (TC) representing the formal law system, on one hand, and the customary courts law representing the informal system, on the other. Though Bergli (2013) supports constitutional rights, the current statutory system in south Sudan is not enough on its own in terms of being a security provider; as a result customary courts must not be removed completely. The above study shows the importance of the inclusion of local customs when dealing with GBV cases.

In Zambia, Makunka (2015) undertook a study to assess the Young Women Christian Association (YWCA) anti gender based violence educational program at the Kitwe centre. The study was necessitated by the alarming statistics of gender based violence cases (GBV). The Zambia police annual crime returns showed an increase in Gender based violence cases. In 2007 , about 5,127 cases were reported to the police, whereas 8,467 cases were reported in 2010.The objectives of the study were:-to determine the characteristics of the clients,-to determine the adequacy of the program qualitatively and quantitatively in addressing gender based violence, to investigate the appropriateness of the instructional tools and techniques used in the Young Women Christian Association anti-gender based violence program and -to examine if the Young Women Christian Association education program has been responding to the needs of the clients. Makunka's research employed a case study design in order to do an in-depth work. The study comprised 73 respondents. Out of these 70 were Young Women Christian Association clients, 2 Young Women Christian Association psychosocial counselors and 1 Young Women Christian Association coordinator. Data was collected using researcher administered questionnaires, observation and face to face semi structured interviews. With regard to the characteristics of the clients this study established that $83 \%$ of the clients were married women and were aged between 26 to 35 years old; $56 \%$ of the clients lived in high density areas. Most of these areas were in the locations where YWCA carry out its anti-gender based violence sensitization campaigns. The Young Women Christian Association was not running any sensitization campaigns in low and medium density residential areas. With regards to the adequacy of the program the study concluded that the program was inadequate in the sense that it focused so much on counselling, leaving out issues of financial assistance, permanent shelter, spiritual counselling and employment after skills training. On busy days such as Monday, Tuesday and Wednesday the number of clients ranged between 3 to 10 persons per day. About 1900-2700 clients visit the centre in a year and about 100 clients visit the shelter annually. The study concluded that the number was low in comparison with the statistics of domestic violence obtained from Zambia Police Victim Support unit and considering YWCA coverage area which was vast. As for the instructional techniques and materials at the time of the study, the following instructional techniques and materials were used: charts, posters, leaflets, visual aids, Education and communication (IEC) materials, press releases, group discussion method, client centered method, awareness campaigns and couple counselling. The clients indicated that they had various needs including financial, spiritual, protection and counselling needs. The study established that most clients' needs were satisfied after seeing a counselor. However they had other needs such as permanent shelter, financial stability which the YWCA program could not meet. The researcher recommended that YWCA should broaden its coverage area where it holds Gender based violence educational sensitization campaigns; and YWCA should produce most of the materials in local languages which most clients could read at ease. The above literature highlights the importance of use of local language in combating gender based violence; however, no study has been carried out on the translation strategies used to translate the materials used in Anti GBV programme.

\subsection{Legal Translation}

The linguist Cao (2007: 12) defines legal translation as "translation of texts used in law and other legal settings". She further explains that the definition includes translation of law 
itself as well as translation of other communications in legal settings. Another scholar, Engberg (2002: 375) agrees with Cao when he defines legal translation as "translation of texts for legal purposes and legal settings". This article has used these two definitions of legal translation as they are based on Cao's definition. As for Engberg (2002: 375), he explains that when one chooses to use his definition, he logically speaking also accepts to use Cao's definition of legal translation. The purpose of legal translation will normally be to produce a target text which will be interpreted in the same way by the receivers who are familiar with the target legal systems as the source text was interpreted by the receivers who are familiar with the source legal system. Even though Cao has one definition for legal translation, she divides legal translations into different categories based on the purpose of the translation, as will be seen in the following section (Cao 2013: 416).

\subsection{Cao's Classification of Legal Translation Based on Purpose}

Cao (2013: 416) has made the following classification of legal translation on the basis of the purpose of the target text:

1. Normative purpose;

2. Informative purpose;

3. General legal or judicial purpose.

The first category contains the production of equally authentic texts. This means that the target text also has legal force. Such texts are, for example, used in connection with statutes in bilingual or multilingual jurisdictions, as well as private documents such as agreements between businesses where it is stipulated in the agreement that both versions have legal force. In this category, the purposes of the source text and the target text are the same. (Cao 2013: 416-417).

The second category contains translations which are supposed to provide the receivers of the target text with information. In this category, only the original source text has legal force. This also means that the source text and the target text may have different purposes (Cao 2013: 417). An example of a purely informative translation is the target text used in this article.

The third category contains translations which are primarily used for information and which are mostly descriptive. This category encompasses, inter alia, translated documents used in a court of law as documentary evidence. Because these types of texts are used in court, they have legal implications. The difference between this category and the second category is that the third category may include texts which do not contain any legal language and they have been written by laymen (Cao 2013:417-418).

\subsection{The Skopos Theory}

According to Munday (2012:122), Skopos is the Greek word for aim or purpose and was introduced into translation theory by Hans Vermeer (1930-2010) as a technical term for the purpose of a translation and of the action of translating. Hans Vermeer developed the skopos theory in the late 1970s using some of Reiss' earlier work (Schjoldager's 2008: 152). The idea behind the skopos theory is that it is possible to translate a specific source text in different ways. The skopos (or the skopoi) of the target text decides how the source text in question should be translated. This also means that the skopos of the target text influences the translator's choice of translation strategies (Nord 2013: 202).

The Six Rules of the Skopos Theory

The skopos theory consists of six main rules (Munday 2001: 79). These rules are:

Rule 1: The Skopos rule explains that the preparation of the target text is decided by its skopos (purposes) (Schjoldager's 2008: 154). As already mentioned, this means that the skopos of the target text decides how the source text in question should be translated.

Rule 2: A target text (TT) is an offer of information in a target culture and target language (TL) concerning an offer of information in a source culture and source language (SL). Here the translator plays a key role in a process of intercultural communication (Munday 2012:123).

Rule 3: A target text is not clearly reversible. This means that the purpose of the target text is not necessarily identical to that of the source text (Munday 2012: 123).

Rule 4: A target text should be internally coherent (Munday 2012: 122). What this basically means is that the target text should make sense to the receivers of the text within the particular communicative situation and target culture (Nord 1997: 32).

Rule 5: The fidelity rule: There should be an adequate relationship between the source text and the translation of the target text. In other words, the relationship adequacy is determined by the skopos of the target text. (Schjoldager 2008: 154).

Rule 6: Rules 1 to 5 of the skopos theory are introduced in a hierarchical order. This means that the skopos rule is the predominant rule (Munday 2012: 122).

\subsection{Vinay and Darbelnet Model}

Vinay and Darbelnet carried out a comparative stylistic analysis of French and English. They identified two general translation strategies, namely, the direct translation and the oblique translation (Vinay and Darbelnet 2004:128). The two strategies comprise seven procedures. Direct translation covers three of them: borrowing, calque and literal translation; while Oblique translation includes transposition, modulation, equivalence and adaptation. Vinay and Darbelnet (2004) also included supplementary procedures such as amplification, deceptive cognates false, explicitation and generalisation. Below is an outline of the procedures:

The Procedures under direct translation have been defined as follows: Firstly, borrowing has been defined as the transfer of the Source language word directly to the Target language. Sometimes borrowing is added to add colour to the Target language, in other instances the borrowed words may retain the Source language pronunciation (baker 1992). Secondly, Calque is a special kind of borrowing where the structure or Source language is transferred in a literal translation. Lastly, 
literal translation is defined as word for word translation.

Vinay and Darbelnet (2004) introduced the following procedures under Oblique translation. Firstly, transposition is defined as the change of one part of speech for another. For example, a translator can noun in the SL to a verb in the TL without changing the sense of the word. Secondly, Modulation has been defined as the changes in semantics and point of view. Thirdly, Equivalence refers to cases where languages describe the same situation by different stylistic or structural means. This strategy is useful when translating idioms and proverbs. Lastly, Adaptation involves the changing the cultural reference when a situation in the source culture does not exist in the target culture.

Furthermore, Vinay and Darbelnet (2004) exemplified other procedures as follows:

We start with amplification which applies when the TL uses more words because of the syntactic expansion. Secondly, deceptive cognates is a structurally similar term in SL and TL, it may deceive the user into thinking that the meaning is the same. Thirdly, explicitation is making sure that all implicit information in the SL is rendered explicit in the TL. Lastly, Generalisation is the use of a more general word in the TT.

\section{Results}

The text was analysed using the Vinay and Darbelnet (2004) taxonomy. However, not all the procedures were exemplified in the analysis of the translation of the document "A Simple Guide to the anti GBV act" from English into Nyanja.

\subsection{Direct Translation Strategies}

\subsubsection{Borrowing}

In the analysis of the translation strategies applied to translate the document" A Simple Guide to the anti GBV act" from English into Nyanja, we discovered a number of borrowed words such as: failo (file),komiti (committee),lipoti (report),lendi (rent), loya (lawyer),membela (member),polisi (police),insipekita (inspector),pepala (paper),biziness (business), apilo (appeal),pulogiramu (programme),komyuniti (community),pulani (plan),ofesi (office), nurse (nesi), sosholo (social)and fadi (fund).Mmabako (2005) states that one may say the above words have now been "nativised in a sense that their phonology has been adapted to reflect the phonology of the borrowing language(s)." It can be argued that borrowed have been modified to fit into the Target language, thereby making it easier to understand in the TT.

\subsubsection{Literal Translation}

This procedure was the most common in the case of the translation of the "Simple Guide to the Anti GBV Act". The results of our study show that the traditional approach to legal translation is generally founded on the principle of fidelity to the source text. Therefore, a lot of emphasis was placed on literal translation, especially in the case of legislation. Our findings do not support the third rule of the skopos theory, which stipulates that a target text is not clearly reversible. In other words, the third rule argues that the purpose of the target text is not necessarily identical to that of the source text (Munday 2012: 123). Below are some of the examples of literal translation identified in the translation of the "Simple Guide to the Anti GBV Act" from English into Nyanja:

Table 1. Examples of Literal Translation

\begin{tabular}{lll}
\hline NO & ENGLISH & NYANJA \\
\hline 1 & $\begin{array}{l}\text { What you need to know about this law } \\
\text { What happens if there is another law that conflicts with what is in } \\
\text { this Act }\end{array}$ & $\begin{array}{l}\text { Zimene mufunika kudziwa zalamulo limeneli } \\
\text { N'ciani cima chitika ngati pali lamulo lina lotsasutsana ndi Zimene zili mu } \\
\text { lamulo ili }\end{array}$ \\
3 & $\begin{array}{l}\text { Denying a person the right to seek employment or engage in any } \\
\text { income generating activity. }\end{array}$ & $\begin{array}{l}\text { Kuletsa Munthu ufuluwo funa nchito kapena kuti acite nchito ili yonse } \\
\text { imene inga mubweretsere ndalama. }\end{array}$ \\
\hline
\end{tabular}

\subsection{Supplementary Procedures}

\section{Generalisation}

The strategy of using a superordinate or a more general word is generally used to overcome a relative lack of specificity in the target language. Baker (1996:26) states that "this is the commonest of strategies for dealing with many types of non-equivalence at wordlevel; hence, she identifies this as a universal feature, whereby things are simplified to make them understandable to the readers."For example:

ST: Which abuses, humiliates or lowers the other person or violates another person's integrity...

TT: Kucita tere kumapweteka munthu, kamatisa munthu, kapena kucepetsa munthu wina yoka pena kuipitsa ulemu wake.

BT: Doing this injures a person, humiliates or lowers another person or to make bad someone integrity.

In the example above the general term Kupitsa has been used to explain the violation of the integrity. In that Kupitsa could mean the following depending on the context; to make bad, damage, destroy, disfigure, denounce and assassinate character.

\subsection{Other Strategies not Exemplified by Vinay and Darbelnet (2004)}

\subsubsection{Direct Transfer}

According Schjoldager (2008: 93) direct transfer is a process during which an item from the source text is transferred directly to the target text without making any changes. In other words, a source-text item is copied from the source text and inserted into the target text. Our study observed that some of the words and phrases were not 
translated, such as: anti GBV, HIV, UN, YWCA, Auditor General, Social Services, Gender, Health, and Education. It may be argued that when choosing the English words in relation to the acronyms and some organisations, it is understandable to the target-text receivers as they are commonly used. Therefore, it is suitable in relation to the skopos (purposes) of the target text, even though it may be argued that complete target-language orientation is preferable. Furthermore, when it comes to the names of institutions, it is sometimes difficult to find a foreign language word that is equivalent in accessible sources like dictionaries, glossaries, or corpora. If the institution itself does not suggest the officially established and acceptable version of its name, the only solution is to borrow the original name and add the translator's version of descriptive translation, or sometimes a calque. It may be the only excuse for using the name of an equivalent institution in the target culture depending on the situation in which the functions of both institutions are similar. However, we must remember that the translation is introduced after the first appearance of the original term for informative purposes, as the most appropriate strategy is still to use the original versions of such names.

\subsubsection{The Use of a Less Expressive Word}

Our findings revealed that translation by a less expressive word was used in different circumstances. For example, sexual abuse has been translated as Kugwirira munthu. It can be argued that the translator opted for this to avoid mentioning sex (chisembwere, chinda, gonana) which is explicit in the target culture as must not be publicly talked about.

\subsubsection{Addition}

The strategy was used in order to provide further information to make it easier for the TT to understand some concepts. Look at the following example:

ST: Ritual killings for the purposes of appeasing spirits.

TT: kupha munthu kwamwambo ndi colinga cofuna kuziziritsira mizimu yaanthu akufa

BT: Killing a person according to tradition and as required for appeasing the ancestral spirits

In the example above ancestral spirit has been added to qualify what is meant by spirit.

\section{Summary Translation Strategies Used in the Translation of Simple Guide to the Anti GBV Act into Nyanja}

Table 2. Translation strategies used.

\begin{tabular}{lll}
\hline NO & Translation strategy & Frequency \\
\hline 1 & Literal translation & 30 \\
2 & Generalisation & 5 \\
3 & Addition & 5 \\
4 & Direction transfer & 10 \\
5 & Use of less expressive word & 9 \\
6 & Borrowing & 20 \\
\hline
\end{tabular}

\section{Conclusion}

In Conclusion, we would like to reiterate that the purpose of translating the "Simple Guide to the Anti GBV Act" was to create a translation that would be understandable for readers with no or little knowledge of the law, thus the translators being forced to simplify the Target Text as much as possible. It is also important to note that the nature of legal texts and their translation often rules out the possibility of annotations or translator's notes within the text itself. Furthermore, there are two things that will always influence the strategies that the translator may use. These are: the purpose of translating, on one hand, and the target audience, on the other. In the case of the "Simple Guide to the Anti GBV Act", the translator employed the following strategies: borrowing, addition, direct transfer, generalisation, use of a less expressive word and literal translation. Zaralka (2007) would support the results that we obtained above As far as he is concerned, borrowings, calques, naturalizations or descriptive translations are commonly used because the first and most critical rule in the translation of such texts (apart from being communicative) is the retention of the source cultural elements. This is mostly applicable to official names of countries, institutions, job titles, and the forenames of the holders of the documents. We also retain the sense (or names) of administrative units, the names of normative acts governing the formats of the documents if they are mentioned, and the references to all forms of proof of authenticity - stamps, watermarks etc. It is even possible to somehow adjust the format of the documents to assure the target reader that the document they are dealing with is the official one.

\section{References}

[1] Baker, M. (1992). In Other Words. London: Routledge.

[2] Bergli. (2013). Gender Based Violence versus human security cases from South Sudan. Retrieved from munin.uit.no/bitstream/handle/10037/5549/thesis.pdf

[3] Cao, B. (2013). Legal Translation Studies.In. In C. \&. Millán (Ed.), The Routledge Handbook of Translation Studies. (pp. 415-424). New York: Routledge.

[4] Engberg et al. (2002). Legal Meaning Assumptions - What are the Consequensec for Legal Interpretation and Legal Translation. International Journal for the Semiotics of Law , International Journal for the Semiotics of Law 15, pages 375-388.

[5] Makunka. (2015). An Assessment of the Young Women Christian Association Anti Gender Based Violence Education Programme of Kitwe District,Zambia. Unpublished.

[6] Mmaboko, E.M. (2005). SABC News in Sotho Language.A case Study in Translation. Unpublished MA Dissertation.

[7] Munday, J. (2012). Introducting Translation Studies. New York: Routledge.

[8] Pedersen. (2014). An anlysis of the macrostrategy and microstragtegies used to translate Ophavsretsloven. Unpublished. 
[9] Restless Development. (2012). Position paper on the Anti Gender based violence Act. Restless Development, ZANEC, Zambia YWCA.

[10] Schjoldager, J. (2008). UnderstandingTranslation with Chapters by Henrik Gottlieb \& Ida.Aarhus/Copenhagen: Academica.
[11] Vinay, J. P. and Darbelnet, J. (1973). Stylistique Comparée du français et de l'anglais. Paris. Didier.

[12] Źrałka, E. (2007). Strategies in the translation of legal textsimplication for translation pedagogy. the Unesco Chair fir Translation Studies and International Communication, 1-13. 